these sections are further subdivided under suitable subheadings.

Dispersed through the book are fascinating accounts of the catalysis of various biochemical processes by enzymes, of which the various vitamins form essential components. Chapters are devoted to meso-inositol and choline, which are regarded as occupying an intermediate position between the vitamins and the amino-acids, as regards both abundance and function. Attention is directed to the paramount importance of aneurine, riboflavine and nicotinic acid for human and animal nutrition. It is of interest that the terminal ' $\theta$ ' is now favoured for the names of the first two of these and also for pyridoxine, in conformity with their character as bases.

There is an interesting discussion of the significance of the biological interchangeability of nicotinic acid and tryptophan, and of the possible biosynthesis of the former from the latter. It is suggested that vitamins $B_{3}, B_{4}$ and $B_{6}$ are of historical interest only, and attention is directed to the fact that $B_{7}, B_{8}$ and $B$, have never existed. This makes the designations vitamins $B_{10}, B_{11}, B_{13}$ and $B_{14}$ for some recently reported nutritional factors a little misleading; but in a subject of such confused origins some anomalies in terminology are inevitable.

Although this is by no means the only modern book on vitamins, it seems clear that it will be regarded for some time to come as the standard of reference on the vitamin $B$ complex.

J. W. Cook

\section{A NEW SURVEY OF HEAT AND THERMODYNAMICS}

A Treatise on Heat (including Kinetic Theory of Gases, Thermodynamics and Recent Advances in Statistical Thermodynamics)

By Prof. M. N. Saha and Dr. B. N. Srivastava. Third edition, thoroughly revised and rearranged. Pp. xii+936. (Allahabad and Calcutta : Indian Press, Ltd., 1950.) 32 rupees.

NE is sometimes inclined either to be unaware of, or to under-estimate, the scope of thermodynamics and the great variety of problems which are amenable to treatment by its methods. It is therefore refreshing to read the new edition of this well-known text-book, especially the latter half, which contains much new material and has been extensively revised.

The twenty years since the first edition appeared have seen a much more extensive application of statistical thermodynamics to specific heats, to lowtemperature phenomena and many other solid-and liquid-state phenomena, to chemical equilibria, ionization, thermal diffusion and to astrophysical problems, a list which is by no means exhaustive.

The third edition of the book not only discusses all these, but also, in the earlier chapters, treats the conventional and classical parts of the subject. The initial treatment is elementary, so that the book is suitable for all levels of university teaching, from first year to graduate study. In view of the rapid increase in knowledge it is a difficult feat to survey and treat a whole subject from its beginnings up to the boundaries of knowledge in one volume; but, on the whole, Prof. M. N. Saha and Dr. B. N. Srivastava have succeeded very well indeed. The book is a pleasure to read, not only from the clarity of its style but also from the obvious enthusiasm with which it has been written.

Most of the criticism which may be made against it is on personal grounds of preference and emphasis rather than of substance. There is, for example, a good deal of elaborate description and discussion of early experiments on heat which have now only limited value. One exception, however, can be made. In this, and I think in all other text-books on heat, the Bunsen ice calorimeter is dismissed as unreliable and of historical interest only, when in fact it is being extensively used as an accurate and reliable instrument in the United States, particularly by the National Bureau of Standards.

Again, in one part of the book there is a curious sequence of subject-matter. Heat engines and their theory come in Chapter 4 before any discussion of the first and second laws of thermodynamics, which are treated in Chapters 5 and 6 respectively. It is not clear why this order should be chosen, since in Chapter 4 the reader is more than once advised to read the two following chapters before proceeding. It is also a pity that modern heat engines, such as the gas turbine and jet engine, should be dismissed in a dozen lines or so.

The practical treatment of refrigeration and the liquefaction of gases is very good indeed; but little mention is made of the importance of the concept of entropy in understanding the production of low temperatures, and the discussion of the third law of thermodynamics is somewhat limited.

The rest of the book is excellent. In particular, the chapters dealing with statistical mechanics, kinetic theory and vapour pressure, and radiation are to be commended. Appropriately enough in a modern monograph on heat, the last two words in the text are "atom bomb". J. F. AtLein

\section{PHYLOGENY OF FLOWERING PLANTS : FACT OR FICTION?}

\section{Families of Dicotyledons}

By Alfred Gundersen. With Introductory Chapters by Chester A. Arnold, Oswald Tippo, Theodor Just, Herbert F. Copeland, J. Herbert Taylor and W. H. Camp. (Plant Science Books, Vol. 25.) Pp. xviii + 238. (Waltham, Mass.: Chronica Botanica Co.; London: Wm. Dawson and Sons, Ltd., 1950.) 4.50 dollars.

IN the ninety-two years since the publication of the 1 "Origin of Species" a great deal of argument but remarkably little fact has been produced about the relationships of the Angiosperms. Two works, "Genera Plantarum", by Bentham and Hooker, and "Die natürlichen Pflanzenfamilien", by Engler and Prantl, both of undoubted value, but without the least trace of phylogenetic pretensions, have appeared. Afterwards the readers of these great works have often assumed, in spite of the facts, that they represented the views of their authors on phylogeny, and much of the argument has centred rather fruitlessly around this assumption.

Meanwhile, neither palæobotany, morphology, anatomy or cytology has thrown any light on the origin of the Angiosperms or of any major group within the Angiosperms which the unbiased observer can regard as unequivocal. Indeed, one may go further and say that no more is known now about the origin of any major group of plants than was known in 1859 . 